\title{
Impacts of Agulhas Leakage on the Tropical Atlantic Western Boundary Systems $\mathscr{O}$
}

\author{
P. CASTEllanos \\ Instituto Oceanográfico, Universidade de São Paulo, São Paulo, Brazil, and Institut de Ciències del Mar, \\ Consejo Superior de Investigaciones Científicas, Barcelona, Spain \\ E. J. D. CAMPOS \\ Instituto Oceanográfico, Universidade de São Paulo, São Paulo, Brazil
}

J. PIERA

Institut de Ciències del Mar, Consejo Superior de Investigaciones Científicas, Barcelona, Spain

O. T. SATO

Instituto Oceanográfico, Universidade de São Paulo, São Paulo, Brazil

M. A. F. Silva Dias

Instituto de Astronomia, Geofísica e Ciencias Atmosféricas, Universidade de São Paulo, São Paulo, Brazil

(Manuscript received 11 December 2015, in final form 15 May 2017)

\begin{abstract}
The influx of warmer and saltier Indian Ocean waters into the Atlantic-the Agulhas leakage-is now recognized to play an important role in the global thermohaline circulation and climate. In this study the results of a $1 / 12^{\circ}$ simulation with the Hybrid Coordinate Ocean Model, which exhibit an augmentation in the Agulhas leakage, is investigated. This increase in the leakage ought to have an impact on the meridional oceanic volume and heat transports in the Atlantic Ocean. Significant linear trends found in the integrated transport at $20^{\circ}, 15^{\circ}$, and $5^{\circ} \mathrm{S}$ correlate well with decadal fluctuations of the Agulhas leakage. The augmented transport also seems to be related to an increase in the latent heat flux observed along the northeastern coastline of Brazil since 2003. This study shows that the precipitation on the Brazilian coast has been increasing since 2005, at the same location and with the same regime shift observed for the latent heat flux and the volume transport. This suggests that the increase of the Agulhas transport affects the western boundary system of the tropical Atlantic Ocean, which is directly related to an increase in the precipitation and latent heat flux along the western coast.
\end{abstract}

\section{Introduction}

It is well known that changes due to greenhouse warming have a significant impact in the oceanic largescale circulation and in the global meridional overturning circulation (MOC; e.g., Garzoli and Matano

Supplemental information related to this paper is available at the Journals Online website: http://dx.doi.org/10.1175/ JCLI-D-15-0878.s1.

Corresponding author: Paola Castellanos, castellanos@icm. csic.es
2011). Therefore, to recognize the variability and the processes that affect the MOC, it is crucial to improve the climate models. The Agulhas system has an important role in the climate system and in the Atlantic MOC through the leakage of warm and saline waters from the Indian to the Atlantic Ocean (Beal et al. 2011). Here we take a more holistic approach and, in particular, consider both the South Atlantic Ocean and Agulhas leakage (AL) as potentially powerful modulators of the MOC and climate variability (Bryden et al. 2005). Furthermore, an increasing trend in the Agulhas leakage (Rouault et al. 2009) may result in an overall salinization of the South Atlantic (Biastoch 
and Böning 2013). The buoyancy forcing associated with the warm and saline Agulhas leakage waters that enter the South Atlantic may strengthen the MOC by enhancing the Atlantic meridional pressure gradients (Weijer et al. 2002).

The Agulhas leakage results from a complex system, a highly nonlinear interplay between the strong western boundary current along the South African coast, the Agulhas Current retroflection, and a strong mesoscale activity (de Ruijter et al. 1999). The Agulhas water masses are constituted from intermediate and thermocline waters that provide the main sources of heat and salt of the warmer upper limb of the Atlantic MOC (Speich et al. 2001; Speich and Dehairs 2008). Recent evidence indicates that about half of the volume transport that enters the South Atlantic through the Agulhas leakage reaches the tropics within one decade, through the Benguela Current, the South Equatorial Current, and the North Brazil Current (Rühs et al. 2013). The retroflection regime of the leakage induces undulatory processes into the South Atlantic that dynamically modulate the MOC (Biastoch et al. 2009). Therefore, the Agulhas leakage variability affects the changes in heat and freshwater fluxes between the Indian and Atlantic Ocean. As a consequence, it influences the decadal variability of the MOC (Biastoch et al. 2008; Haarsma et al. 2011). Examples of Agulhas leakage acting as a source of decadal MOC variability have been reported in numerical experiments (Knorr and Lohmann 2003; Haarsma et al. 2011) where a gradual warming of the Southern Ocean during a deglaciation period could induce a resumption of the interglacial mode of the thermohaline circulation. In the other direction, a decrease in Agulhas leakage due to the northward migration of the Subtropical Front would cause a cooling beyond typical ice age temperatures (Knorr and Lohmann 2003).

This study evaluates the impact of the Agulhas leakage in the South Atlantic and its effects in the western boundary system of the tropical region. Section 2 provides a description of the data source and methods used in the analysis. In section 3, the Agulhas leakage is estimated. The interdecadal variability analysis is specified in section 4 . The trends in volume transport, heat, and precipitation are described in section 5 and the regime shifts are explained in section 6 . We close with a concluding discussion in section 7 .

\section{Data and methods}

\section{a. Ocean model}

This study was based on the analysis of an experiment with a high-resolution implementation of the

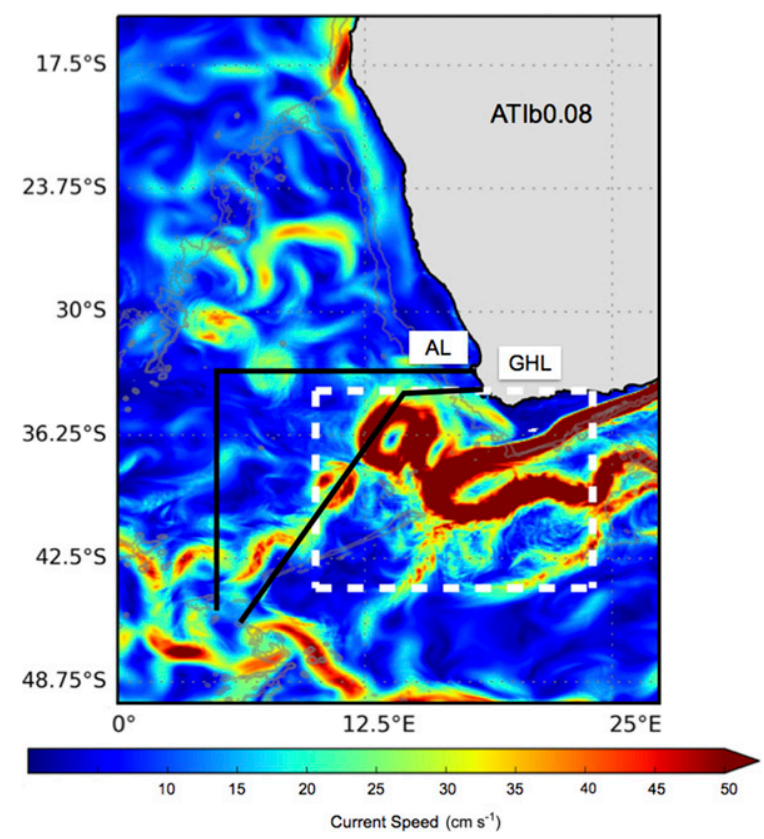

FIG. 1. Snapshot of the surface current speed $\left(\mathrm{cm} \mathrm{s}^{-1}\right)$ for February 2008, based on a 6-day resolution time series from the ATIb0.08 simulation. The sections used to compute the AL transports are marked with black lines. The position of the retroflection is in white.

Hybrid Coordinate Ocean Model (HYCOM; Bleck 2002; Halliwell 2004). This model is characterized by its ability to smoothly interchange the vertical layers between isopycnal, terrain-following, or $z$-level coordinates, optimizing its applicability to different oceanic processes and conditions (Bleck 2002; Halliwell 2004). The high-resolution HYCOM simulation, hereafter referred as ATIb0.08, is one-way nested within a semiglobal coarser-resolution $\left(1 / 4^{\circ}\right)$ simulation (ATIa0.25). This "nesting" approach is detailed in Castellanos et al. (2016). The variables calculated by the higher-resolution model are relaxed to the results of a coarser run, using a $2^{\circ}$-wide buffer zone and a 24-day relaxation time scale during the period 1960 2010. The experiment ATIb0.08 was forced with monthly means of NCEP-NCAR reanalyses products (Kalnay et al. 1996; http://www.esrl.noaa.gov/psd/), from 1960 to 2010 with a $1 / 12^{\circ}$ horizontal resolution and 22 hybrid vertical layers. Near the surface, the K-profile parameterization (KPP; Large et al. 1994) is used to represent the mixed layer evolution.

The bathymetry was extracted from the NOAANGDC ETOPO5. For initial and lateral boundary conditions, the experiment used outputs of a coarserresolution implementation to a geographical domain that includes the Atlantic and Indian Ocean basins: $70^{\circ} \mathrm{S}-60^{\circ} \mathrm{N}, 98^{\circ} \mathrm{W}-114^{\circ} \mathrm{E}$. The domain of ATIb0.08 spans 


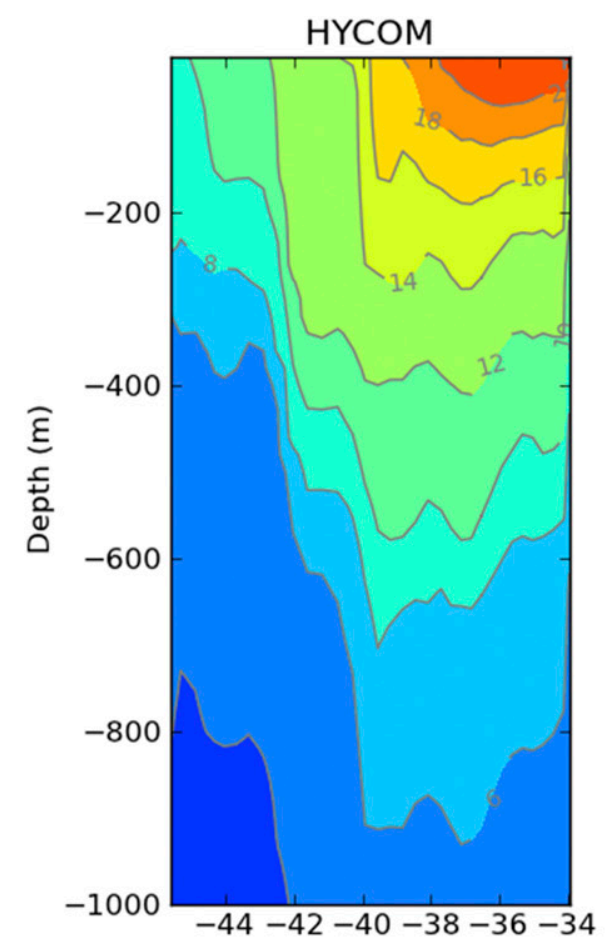

\section{Bonus Good Hope Cruise}
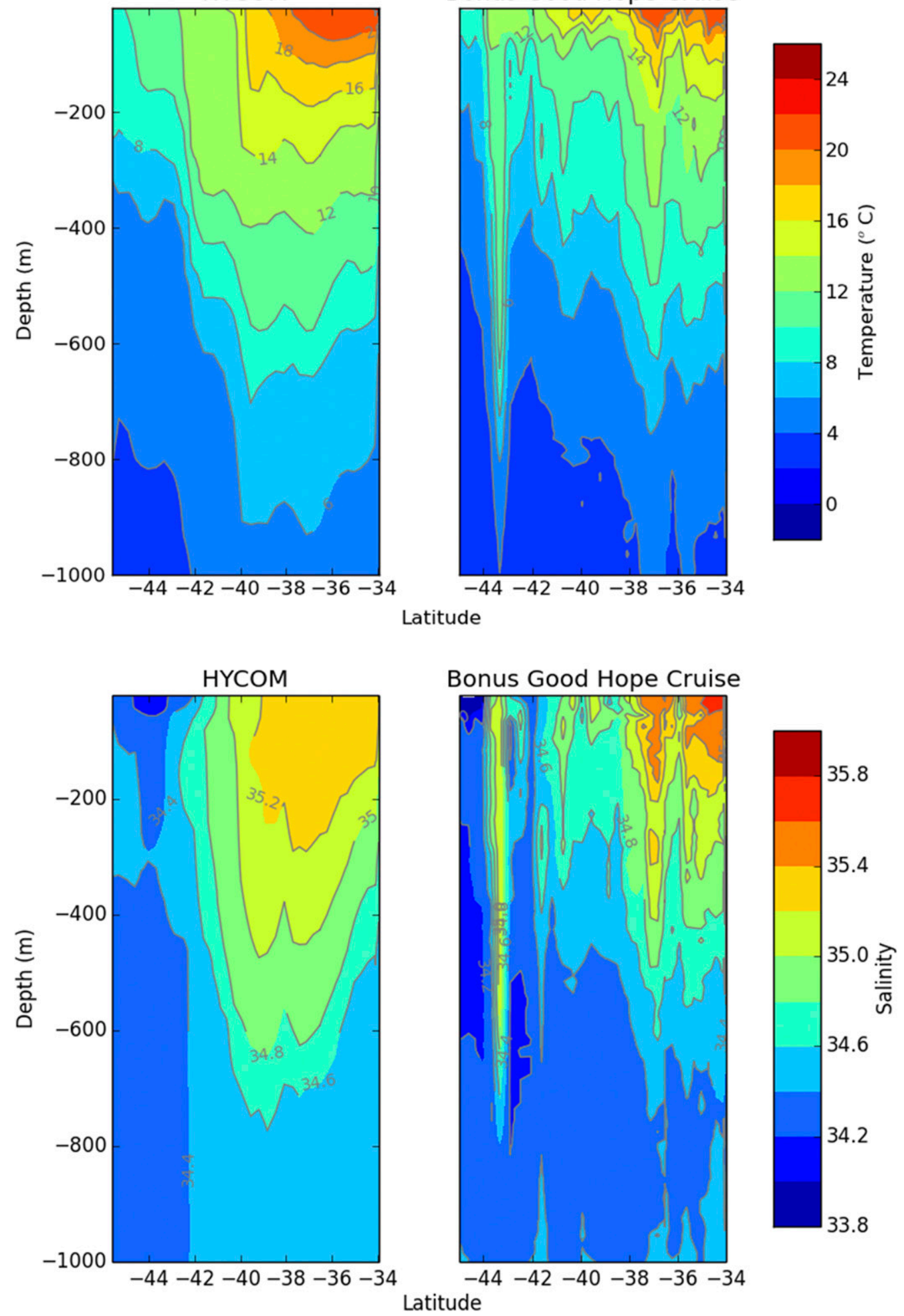

FIG. 2. Vertical sections of (top) temperature and (bottom) salinity along the GHL, showing data from (left) ATIb0.08 and (right) the Bonus GoodHope Cruise. 

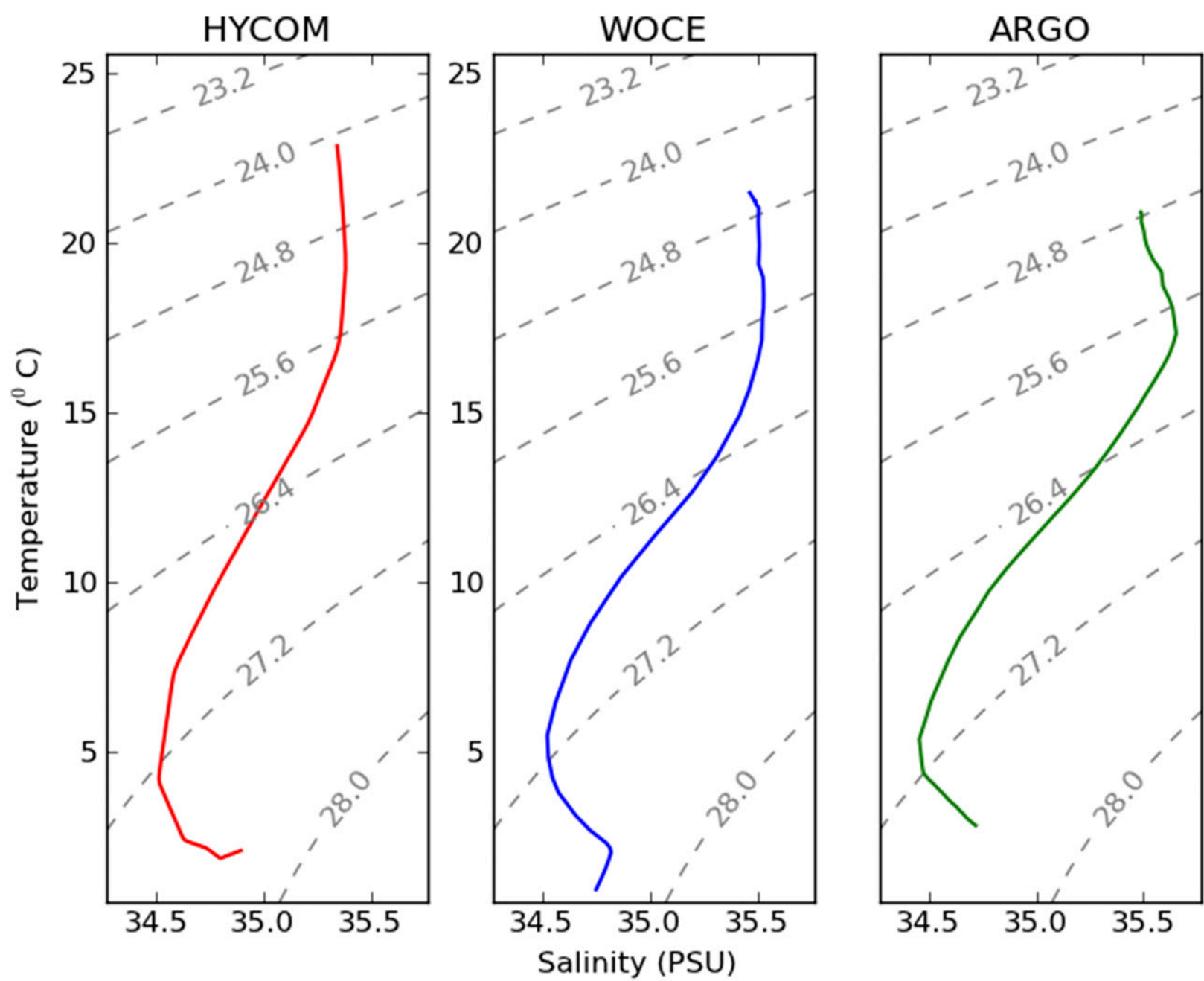

FIG. 3. For the Agulhas Current averaged between 2000 and $2005, T-S$ diagrams at $34.6^{\circ} \mathrm{S}, 28.4^{\circ} \mathrm{E}$ for the ATIb0.08, WOCE, and Argo data.

the South Atlantic Ocean, from $50^{\circ} \mathrm{S}$ to $20^{\circ} \mathrm{N}$ and from $80^{\circ} \mathrm{W}$ to $40^{\circ} \mathrm{E}$. ATIb0.08 has eddy-resolving horizontal resolution on a Mercator projection. The salinity field was allowed to evolve freely and no river runoff was used. The temperature was relaxed to the forcing field, with 120-day relaxation time scale. The density in this model simulation is expressed as $\sigma_{T}$, where $T$ indicates temperature, in which the effects of pressure are not considered.

\section{b. Transport, heat flux, and precipitation trends}

The integrated transport from the ocean surface to the depth of isopycnal $\sigma=25.5 \mathrm{~kg} \mathrm{~m}^{-3}$ was calculated across four transects: $30^{\circ}, 20^{\circ}, 15^{\circ}$, and $5^{\circ} \mathrm{S}$. The Agulhas transport was calculated using as reference the position of the GoodHope line (GHL; Beal et al. 2011), as indicated in Fig. 1. The surface net heat flux and the latent heat flux data were provided by objectively analyzed air-sea fluxes (OAFlux), version 3, from the Woods Hole Oceanographic Institution (Yu et al. 2008). The surface net heat balance takes into account the contribution from radiative heat fluxes (shortwave and longwave radiation) and turbulent fluxes (latent and sensible heat). In this dataset, the radiative flux components were provided by the International Satellite Cloud Climatology Project (ISCCP) (Zhang et al. 2004). The turbulent fluxes were estimated from surface meteorological fields derived from satellite remote sensing and reanalysis outputs. The turbulent heat fluxes in the OAFlux project are computed using the COARE bulk flux algorithm, version 3.0, detailed in Fairall et al. (2003). It is based on bulk aerodynamics, derived from the Monin-Obukhov similarity approach established originally by Liu et al. (1979). Global maps of net heat flux with $1^{\circ}$ resolution are available at monthly and daily resolution. The data span from 1985 

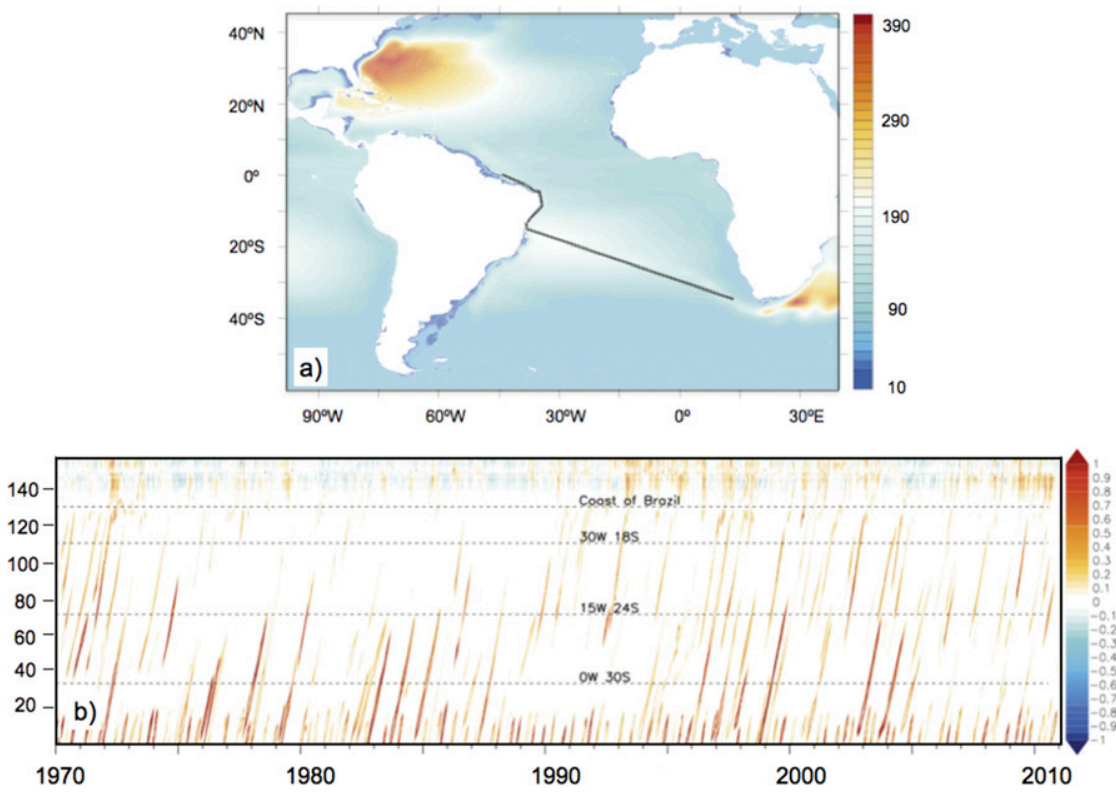

FIG. 4. (a) Snapshot of the depth (m) of isopycnal $\sigma=25.5 \mathrm{~kg} \mathrm{~m}^{-3}$. (b) Hovmöller diagram of the EKE $\left(\mathrm{m}^{2} \mathrm{~s}^{-2}\right)$ anomaly relative to the 40 -yr mean from the ATIb0.08 simulation along the transect indicated in (a). Positive values indicate an increase in the EKE. The $y$ axis represents the transect from right (north of Agulhas leakage) to left (Brazilian coast).

to 2009 for the net heat flux and up to 2014 for the turbulent heat fluxes. The monthly averaged precipitation data derived from the observing system maintained by Fundação Cearense de Metereologia e Recursos Hídricos (FUNCEME), Brazil, were used in this study to calculate the total precipitation average from the 33 stations over $2.5^{\circ}$ and $4^{\circ} \mathrm{S}$ along the coast, during the period from 1985 to 2014.

\section{Agulhas leakage}

Temperature and salinity vertical profiles from the Bonus GoodHope Cruise (February-March 2008; Speich and Dehairs 2008) are compared with ATIb0.08 output during the same time period; see the transect in Fig. 1, GHL (from the cruise), and AL (ATIb0.08 simulation). The signal of the Agulhas Current system extends deeper in the model simulation than seen in the cruise data, indicating that the Agulhas Current may be somewhat "more" barotropic in ATIb0.08. In the upper $500 \mathrm{~m}$, the temperature profiles (Fig. 2, top) are mostly similar with the $12^{\circ} \mathrm{C}$ isotherm extending to about $42^{\circ} \mathrm{S}$ and to a depth of $400 \mathrm{~m}$ in both the model and cruise data. Similarly, for the salinity field (Fig. 2, bottom), the 35.2 isohaline extends to about $38^{\circ} \mathrm{S}$ and to $400 \mathrm{~m}$. In the salinity profile, the ATIb0.08 underrepresents the salinity values by $\sim 0.2$ psu.

Transports of Agulhas leakage are estimated on the monthly averages of the model output. The section labeled AL in Fig. 1 was used for the integration rather than the GoodHope line due to a westward bias of the retroflection position in the ATIb0.08 simulation. A proxy for interocean exchange was computed for this study to extract the variability and trends of all the Indian Ocean water that moves into the South Atlantic as Agulhas leakage. An Eulerian method, similar to that of Van Sebille et al. (2010), was applied, using thresholds in temperature and salinity based on those used by Loveday et al. (2014) for northwestward transport across the GoodHope line.

Figure 3 shows a 5-yr average of temperature and salinity properties in the area of $34.6^{\circ} \mathrm{S}, 28.4^{\circ} \mathrm{E}$ in the Agulhas Current. ATIb0.08 was able to reproduce the temperature and salinity properties as compared with WOCE climatology and Argo floats over the region. The main Agulhas water masses from the model have densities around $25.6 \mathrm{~kg} \mathrm{~m}^{-3}$. The main water mass contribution, at depth between densities of 27.5 and $26.5 \mathrm{~kg} \mathrm{~m}^{-3}$, comes from the Antarctic Intermediate Water (AAIW).

\section{Anomalies in the southern and tropical Atlantic Ocean}

To examine the sensitivity of the ATIb0.08 simulation to the interannual and decadal changes in the temperature and salinity signals in the southern and tropical Atlantic, we calculated their anomalies over 

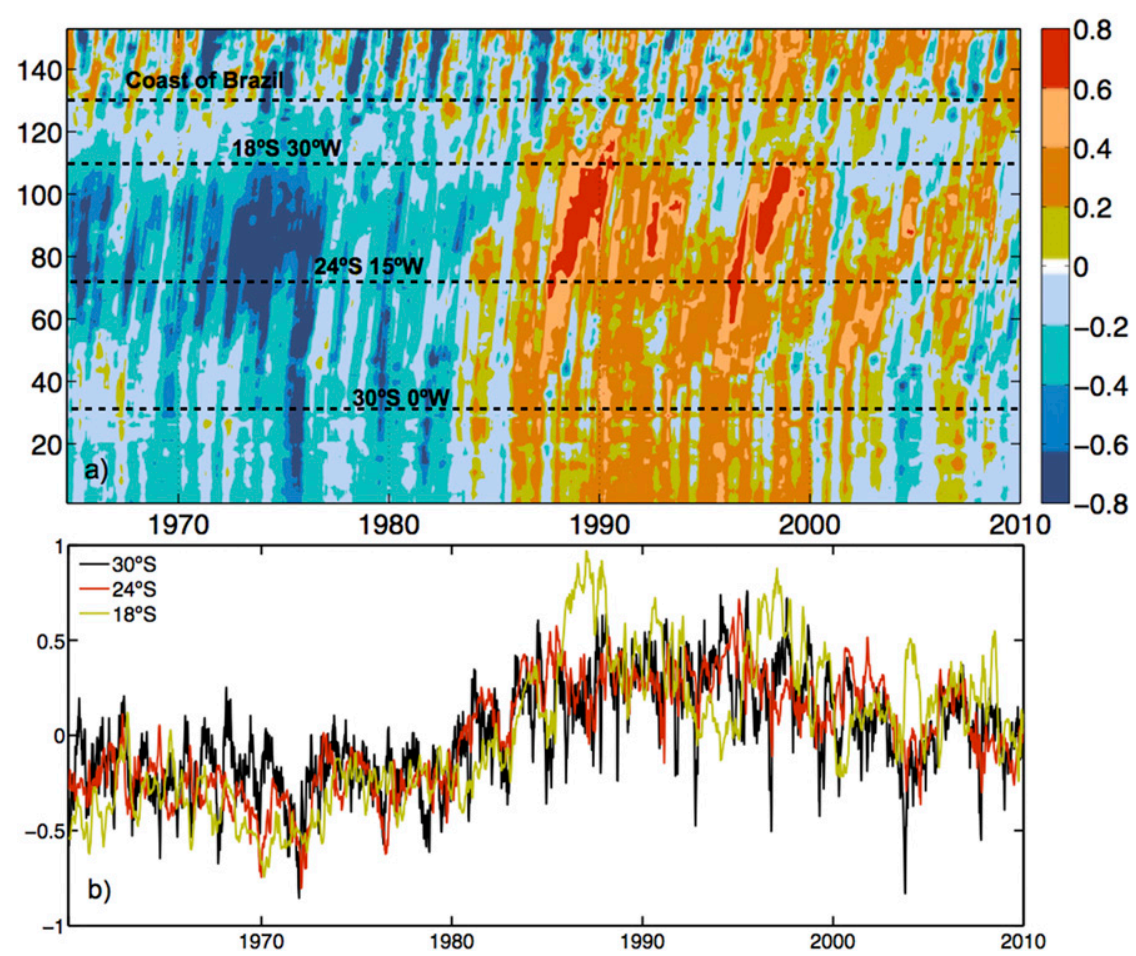

FIG. 5. (a) Hovmöller diagram of the temperature $\left({ }^{\circ} \mathrm{C}\right)$ anomaly averaged over the depth of isopycnal $\sigma=25.5 \mathrm{~kg} \mathrm{~m}^{-3}$ relative to the 40 -yr mean from the ATIb0.08 simulation along the transect indicated in Fig. 4a. The $y$ axis represents the transect from right (north of Agulhas leakage) to left (Brazilian coast). (b) Time series of latitudinal mean temperature between $30^{\circ}$ and $23^{\circ} \mathrm{S}$ (black line), $24^{\circ}$ and $17^{\circ} \mathrm{S}$ (red line), and $18^{\circ}$ and $10^{\circ} \mathrm{S}$ (yellow line).

the depth of the isopycnal $\sigma=25.5 \mathrm{~kg} \mathrm{~m}^{-3}$ relative to the last 40 years (1970-2010). This isopycnal is the best representation of the intrusion of the Indian water in the Atlantic from the ATIb0.08 simulation, which is depicted in Fig. 3.

The westward propagation of the anomalies along the transect is shown in the Hovmöller diagrams (see Fig. 4a). These represent the space-time evolution of the anomalies of eddy kinetic energy (EKE; Fig. 4b), temperature (Fig. 5a), salinity (Fig. 6a), and the depth of the isopycnal $\sigma=25.5 \mathrm{~kg} \mathrm{~m}^{-3}$ (Fig. 7) for the 40 years (1970-2010) of the ATIb0.08 simulation.

In the Hovmöller diagrams, the vertical axis represents the points along the transect from the Agulhas retroflection region to the western equatorial Atlantic. Analyzing from the lower right corner of the diagrams, the anomalies that started at the eastern side of the basin propagated across the South Atlantic and beyond. Along the Brazilian coast and across the equator, the propagation became much faster. The predominant propagation to the northwest indicates an abrupt change since 1985 , followed by a rapid rise in oceanic temperature and salinity (Figs. 5a and 6a, respectively) with impacts on the tropical and the equatorial bands.
Figure 4b exhibits intense EKE anomalies from the Agulhas region that are persistent during the entire period. The EKE anomaly additionally shows a faster propagation during the last two decades, with changes over $1 \mathrm{~m}^{2} \mathrm{~s}^{-2}$ across the South Atlantic. The signal was maintained all the way to the western boundary. Temperature and salinity time series (Figs. 5b and 6b) show a clear change from 1985 to 2003 . Both signals appear to originate from the Agulhas region and propagate toward the coast of Brazil, as indicated in the Hovmöller diagrams in Figs. 5a and 6a.

Figure 7 represents the anomalies in the depth of the isopycnal $\sigma=25.5 \mathrm{~kg} \mathrm{~m}^{-3}$ showing a shift to more positive values from 1985 onward. Figure 7 depicts the northwestward propagation of the anomalies. The results suggest a subsidence in the isopycnal depths, spreading out across the Atlantic. The tilted thin lines may be rings that cross the Atlantic at that isopycnal depth.

The temperature-salinity $(T-S)$ diagram in Fig. 8 shows the transition of the water masses toward the north from $50^{\circ} \mathrm{S}$ along $45^{\circ} \mathrm{W}$. The isopycnals 26.5 and $27 \mathrm{~kg} \mathrm{~m}^{-3}$ mark the transition between the South Atlantic Central Water (SACW) and the AAIW; the SACW shallows at $25.5 \mathrm{~kg} \mathrm{~m}^{-3}$. According to Stramma and 

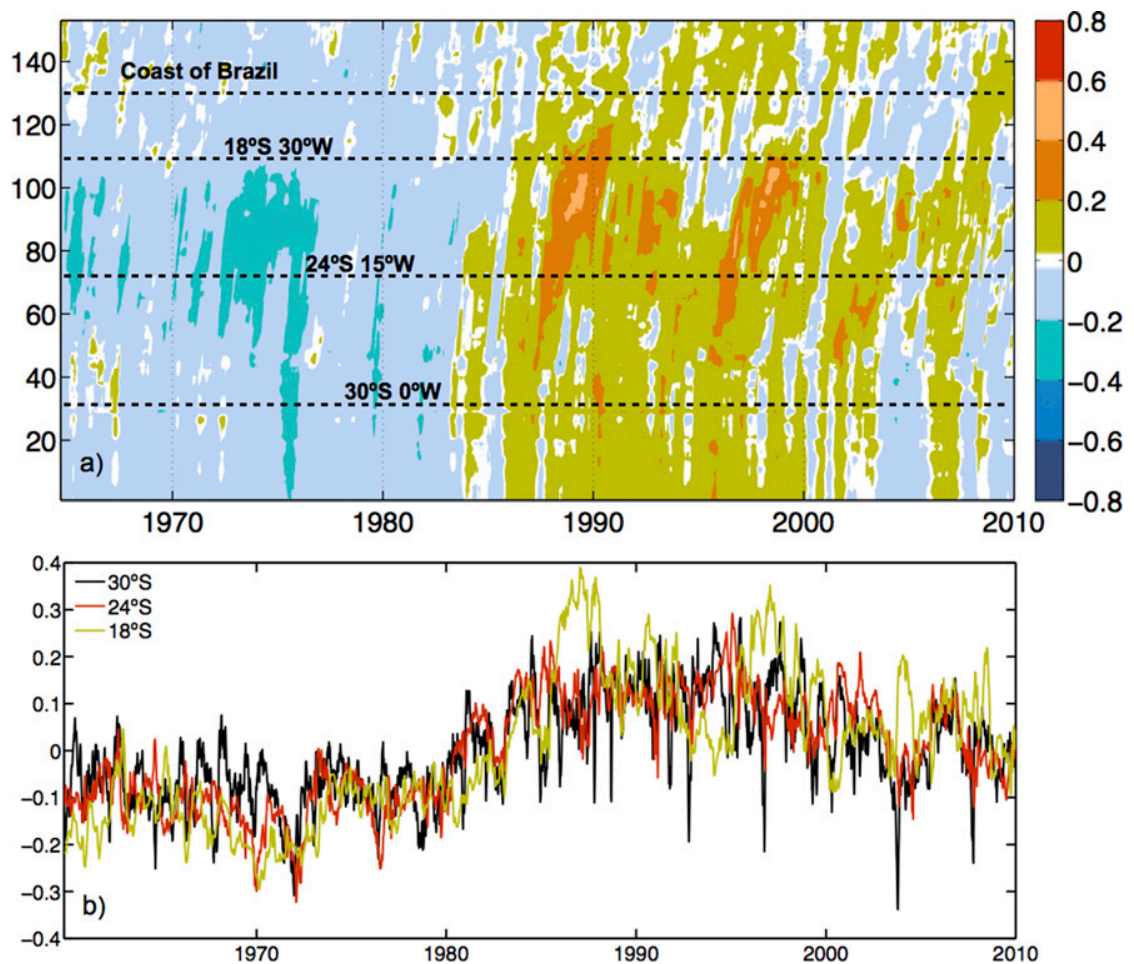

FIG. 6. (a) Hovmöller diagram of the salinity (psu) anomaly averaged over the depth of isopycnal $\sigma=25.5 \mathrm{~kg} \mathrm{~m}^{-3}$, for the 40 years from the ATIb0.08 simulation along the transect indicated in Fig. 4a. The $y$ axis indicates the transect from right (north of Agulhas leakage) to left (Brazilian coast). (b) Time series of latitudinal mean salinity between $30^{\circ}$ and $23^{\circ} \mathrm{S}$ (black line), $24^{\circ}$ and $17^{\circ} \mathrm{S}$ (red line), and $18^{\circ}$ and $10^{\circ} \mathrm{S}$ (yellow line).

England (1999), part of the SACW is not subducted at the subtropical convergence zone, where the Agulhas Current redistributes the contribution of the Indian Central Water (ICW). The water that remains in the top layers can be traced from Namibia to the coast of Brazil, joining the equatorial current system. The propagation of anomalies across the Atlantic confirms that waters from Agulhas leakage reach the equatorial region.

\section{Positive trends}

Trends were estimated from the time series by removing the long-term mean and a seasonal signal that

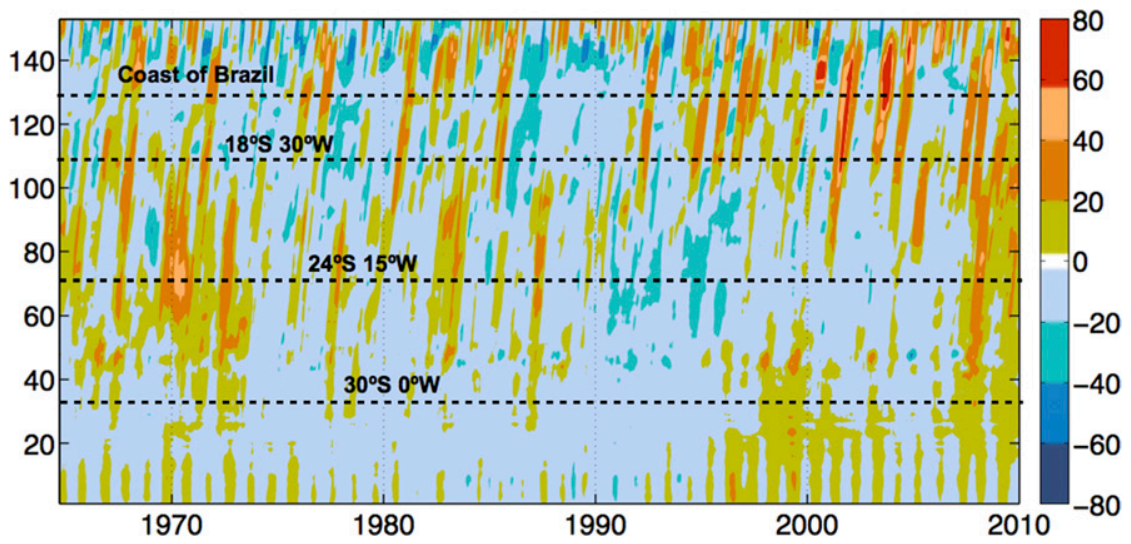

FIG. 7. Hovmöller diagram of the isopycnal $\sigma=25.5 \mathrm{~kg} \mathrm{~m}^{-3}$ depth (m) anomaly from the ATIb0.08 simulation along the transect indicated in the Fig. 4a. 


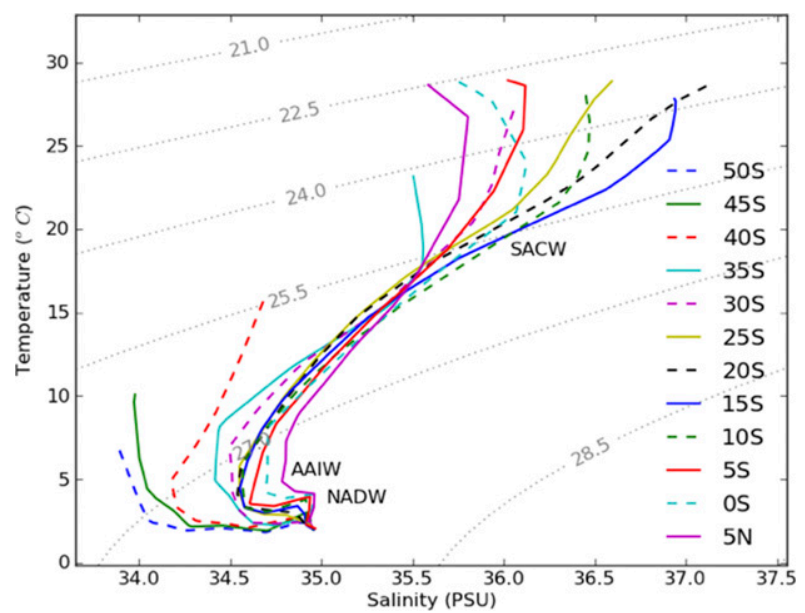

FIG. 8. Along $45^{\circ} \mathrm{W}$ across the southern and tropical Atlantic from the ATIb0.08 simulation, $T-S$ diagram showing the distribution and characteristics of the water masses present at different latitudes.

was adjusted by a least squares fit. In Fig. 9, the gray lines represent the model with a temporal resolution of 6 days, while the black line is a smoothed line to minimize the high-frequency variability. The statistical analysis was applied to the original time series.

To assess the statistical significance of the trends, the validity of the null hypothesis was tested. That is, the trends are found by chance by running experiments based on Monte Carlo simulations. For these experiments, time series were built by generating random data with the same number of statistically independent samples, mean, and standard deviation as the original time series. For each randomly generated time series, the trend was estimated using exactly the same methodology applied for the original series. A total of $10^{6}$ simulations were performed and the result is that these trends are statistically significant to within a $95 \%$ (volume transport and precipitation data) and $99.99 \%$ (heat flux data) confidence level.

\section{a. Volume transport}

To support the hypothesis that the effects of the decadal increasing trend in Agulhas leakage can have an impact on the South Atlantic dynamics (Dong et al. 2011), the meridional volume transports at different latitudes were calculated. Figure 9 shows the volume transport in Agulhas leakage and the integrated transport from surface to the depth of the isopycnal $\sigma=25.5 \mathrm{~kg} \mathrm{~m}^{-3}$. From the HYCOM monthly data, the meridional volume transport $V$ is calculated as

$$
V=\int_{z}^{\theta} v(x, y, z) d x d y d z
$$

where $\theta$ is longitude, $z$ is depth for the isopycnal $\sigma=25.5 \mathrm{~kg} \mathrm{~m}^{-3}$, and $v$ is the meridional component of the velocity (in the coordinate $x, y$ ). The transport was estimated for the entire cross sections at $5^{\circ}, 15^{\circ}, 20^{\circ}$, and $30^{\circ} \mathrm{S}$. The observed meridional transports showed $p$ values of 0.0367 (integrated volume transport at $5^{\circ} \mathrm{S}$ ), 0.0499 (integrated volume transport at $15^{\circ} \mathrm{S}$ ), 0.0499 (integrated volume transport at $20^{\circ} \mathrm{S}$ ), and 0.0371 (Agulhas leakage).

The area-averaged total transport of Agulhas leakage changed by $1.3 \mathrm{~Sv}\left(1 \mathrm{~Sv} \equiv 10^{6} \mathrm{~m}^{3} \mathrm{~s}^{-1}\right)$ over the $35-\mathrm{yr}$
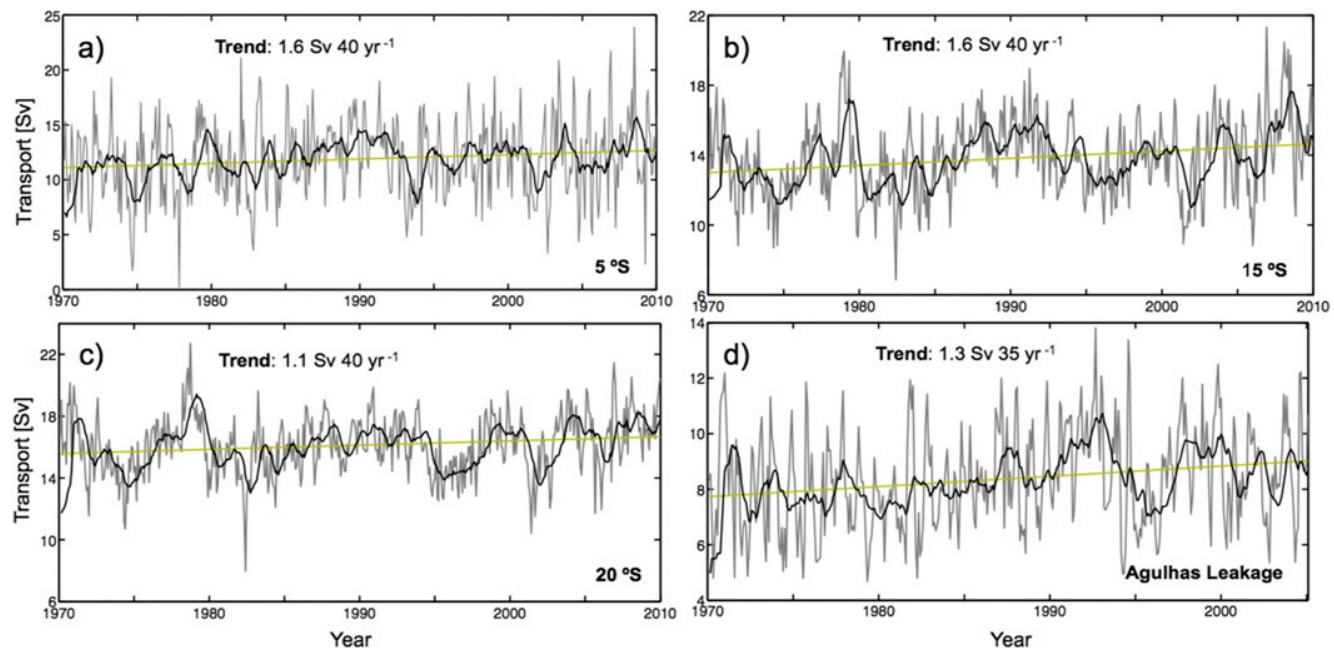

FIG. 9. Zonally integrated volume transport averaged over the depth of isopycnal $\sigma=25.5 \mathrm{~kg} \mathrm{~m}^{-3}$ from the ATIb0.08 simulation during the 1970-2010 period and its long-term trend at (a) $5^{\circ}$, (b) $15^{\circ}$, and (c) $20^{\circ} \mathrm{S}$, and (d) in the Agulhas leakage. The gray lines represent the monthly resolution data and the black lines the 6-month filtered data. The linear fit over the entire time range, indicated with green lines, represents the long-term trend. 


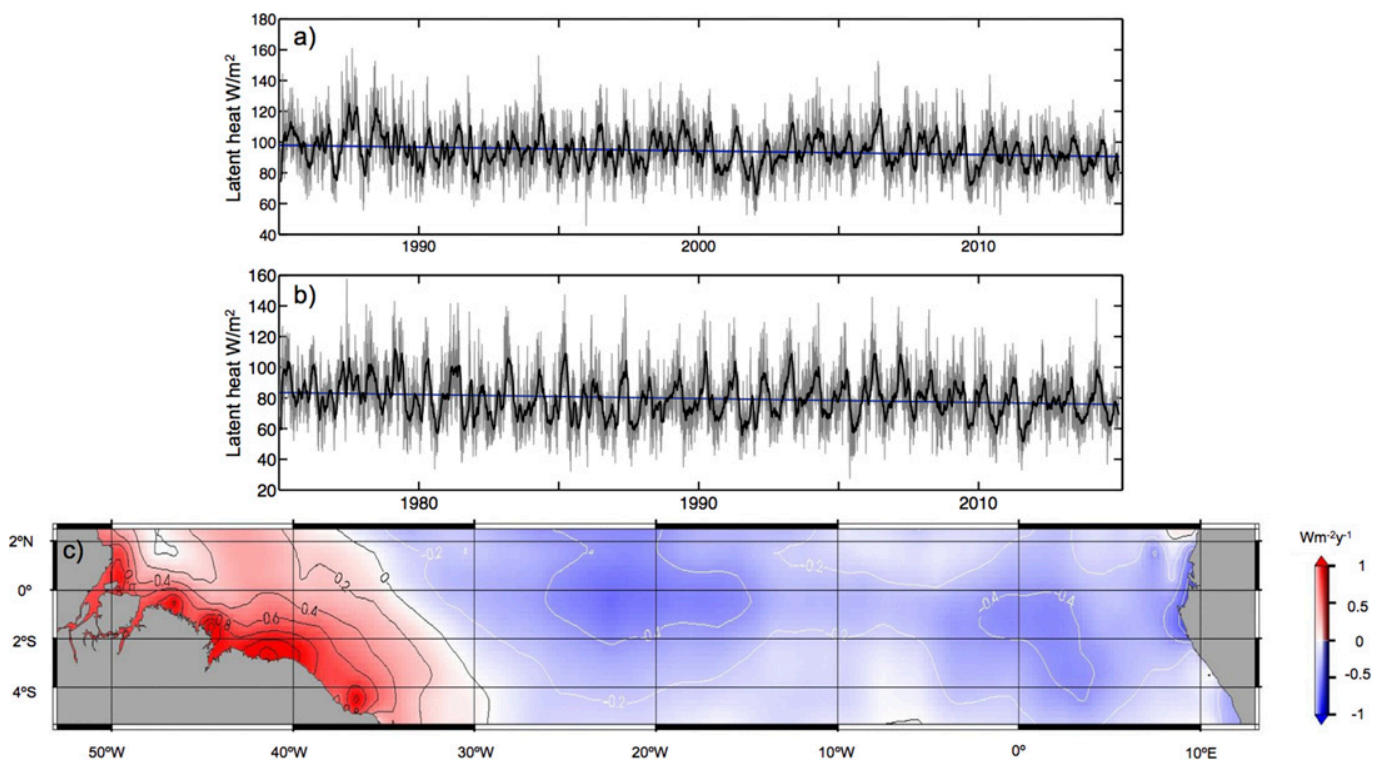

FIG. 10. Time series of the latent heat flux averaged over (a) the central box (between $30.5^{\circ} \mathrm{W}$ and the $0^{\circ}$ meridian line) and (b) the eastern box (east of the $0^{\circ}$ limited between $3^{\circ} \mathrm{S}$ and $2.5^{\circ} \mathrm{N}$ ). The gray lines are the monthly data and the black lines the 6-month filtered data. The blue line represents the linear trend. (c) The latent heat flux trend $\left(\mathrm{W} \mathrm{m}^{-2} \mathrm{yr}^{-1}\right.$ ) over the region.

period in the retroflection region within $36^{\circ}-4^{\circ} \mathrm{S}, 10^{\circ}-$ $20^{\circ} \mathrm{E}$. Therefore an increasing trend in the volume transport is clearly evident in the leakage (Fig. 9d). Also, in the period of $1970-2010$, a positive trend $(1.1 \mathrm{~Sv})$ is found in the integrated transport at $20^{\circ} \mathrm{S}$ (Fig. 9c); at $15^{\circ} \mathrm{S}$, there is a total change of $1.6 \mathrm{~Sv}$ (Fig. $9 \mathrm{~b}$ ); and as far as the tropical region at $5^{\circ} \mathrm{S}, 1.6 \mathrm{~Sv}$ (Fig. 9a).

\section{b. Latent heat flux and precipitation}

The trends in transport can be related to changes in the water column properties in the southern and tropical Atlantic (Biastoch et al. 2008; Haarsma et al. 2008; Dong et al. 2011). Concerning the ocean-atmosphere fluxes, time series of the surface net heat flux in the tropical Atlantic region were calculated. The latent heat flux is expressed as a positive number in the upward direction, when it goes from the ocean to the atmosphere (i.e., the ocean loses heat).

To recognize a possible difference between the western and eastern side of the Atlantic, time series of the daily resolution OAFlux latent heat fluxes (between 1985 and 2014) were analyzed. The trends in the latent heat flux were produced by averaging these values at three boxes between $2^{\circ} \mathrm{N}$ and $5.5^{\circ} \mathrm{S}$ : the eastern box between $0^{\circ}$ longitude and the eastern coast boundary, the central box between $32.5^{\circ} \mathrm{W}$ and $0^{\circ}$, and the western box between $32.5^{\circ} \mathrm{W}$ and the western boundary of the ocean. Time series plots in Fig. 10 highlight the variability and trends in the boxes defined above. The time series in eastern and central boxes (Figs. 10a,b) exhibit a decrease of -7.2 and $-7.1 \mathrm{~W} \mathrm{~m}^{-2}$, respectively, during the last 30 years. This suggests that, in those boxes, the ocean lost less heat to the atmosphere by latent heat flux. Furthermore, the spatial distribution of the latent heat flux trends (Fig. 10c) suggests that the trends are different for each region of the ba$\sin$. On the western side, there is an increase in the loss of latent heat (i.e., the ocean is losing more latent heat in the analyzed period), whereas in the central and eastern regions the trends are in the opposite direction, suggesting that there are different mechanisms that act on each side.

Additionally, Fig. 11a shows the monthly mean (gray line) of the latent heat flux in the western region, and its 6-month running mean (blue line) to minimize the high-frequency variability. The results indicate that in these locations the ocean has a positive surface net heat flux where, on average, it gains $62 \mathrm{~W} \mathrm{~m}^{-2}$ (not shown). To accomplish this balance, the latent heat flux contributes $122 \mathrm{~W} \mathrm{~m}^{-2}$ of heat loss to the atmosphere on average (Fig. 11a). For the study region, we observed a positive trend in the latent heat flux corresponding to a total loss of $21.1 \mathrm{~W} \mathrm{~m}^{-2}$ in the 30 -yr period (i.e., the ocean is losing more heat to the atmosphere).

To examine the impacts on the western region near Brazil, precipitation data at two points near the coast $\left(2.5^{\circ}\right.$ and $\left.4^{\circ} \mathrm{S}\right)$ were analyzed for the period $1985-2014$. 

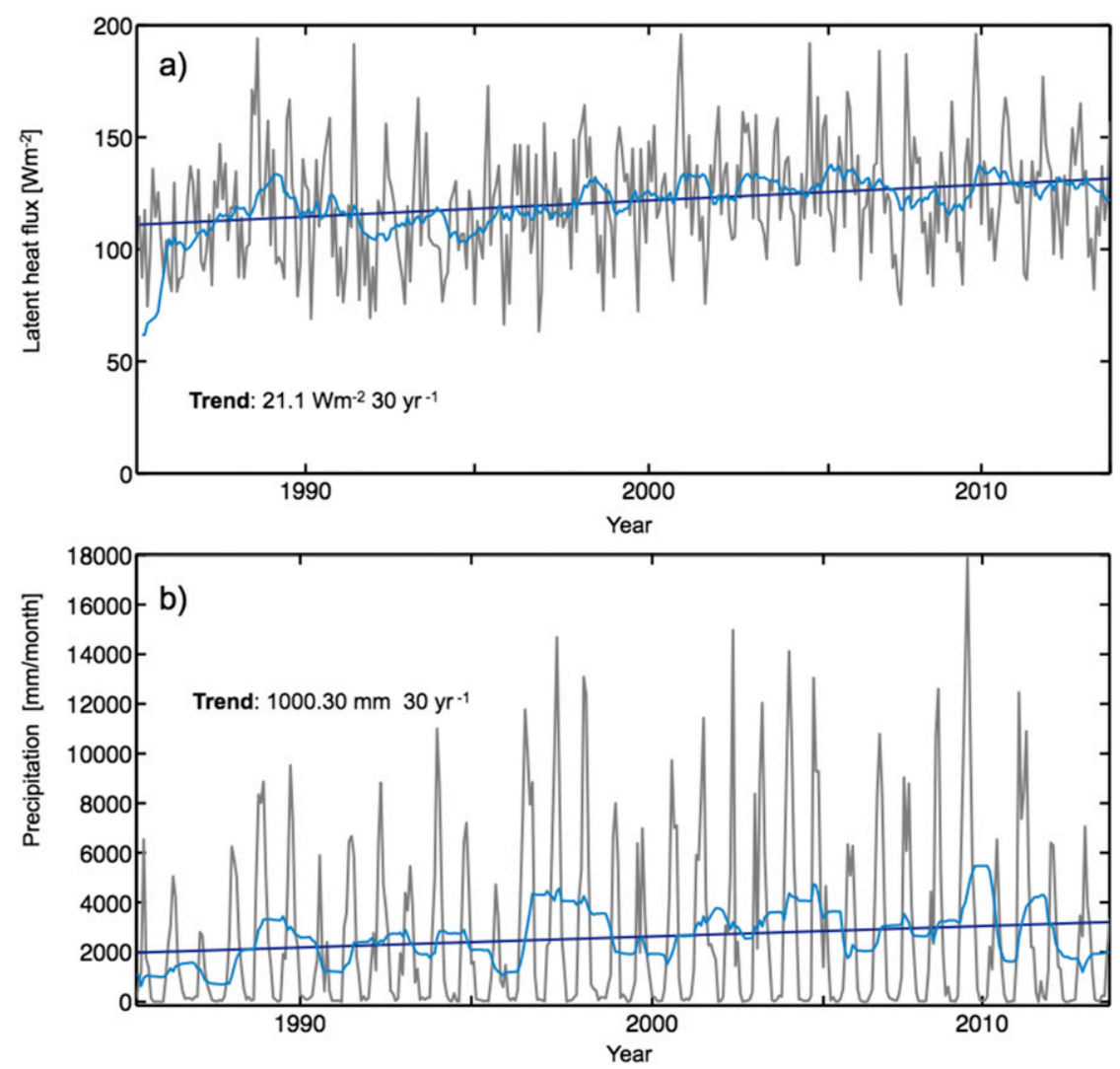

FIG. 11. Time series of the mean (a) latent heat flux (averaged between $1.5^{\circ}$ and $3.5^{\circ} \mathrm{S}$ at $38.5^{\circ} \mathrm{W}$ ) and (b) precipitation (averaged between $2.5^{\circ}$ and $4^{\circ} \mathrm{S}$ along the coastline) at monthly (gray) and 6-month filtered (blue) resolutions from 1985 and 2014. The linear fit represents the long-term trend. Positive latent heat flux means upward flux (from ocean to atmosphere).

Figure $11 \mathrm{~b}$ displays the variability and trend of the total precipitation at 33 meteorological stations along the coast. The rainfall season is clear in the time series, with periods of high and low rainfall. Additionally, interannual variability with increasing trend is observed during the last 30 years. Hounsou-gbo et al. (2015) identified a rainfall regime in which the sea surface temperature in the southern tropical Atlantic is positively correlated with strong positive rainfall anomalies. The results of the present work are consistent with Hounsou-gbo et al. (2015), suggesting that rainfall regime is sensitive to changes in the variability of the latent heat flux. The latent heat flux and precipitation trends are statistically significant at $99 \%$ and $95 \%$ confidence intervals, with $p$ values of 0.0499 (latent heat) and 0.0500 (precipitation), respectively.

\section{Regime shift}

Regime shifts are large, abrupt, and persistent changes in the structure and functions of the system. To recognize the possible connections between trends in
Agulhas leakage and the integrated transport, as well as with the latent heat flux and precipitation, regime shifts were calculated using the cumulative deviation test method for each time series. The test is based on a cumulative sum method (CUSUM; Rodionov 2004). The CUSUM for a given time is given by

$$
C_{i}=\Sigma x_{i}
$$

where $C_{i}$ is a monotonically increasing function for nonnegative $x_{i}$ values. CUSUM is essentially a measure of the area under the curve; thus, it is as if there was a deviation (change) in the data sequence from the background noise level. In the case of a regime shift, the slope of such a monotonically increasing curve would change (with a steeper or shallower slope).

The relation between the transport along the southern and tropical Atlantic transects and the Agulhas leakage can be explained by the time lags in the regime shifts of the integrated volume transport, which can be seen in Fig. S1 in the supplemental material together with the respective correlation 


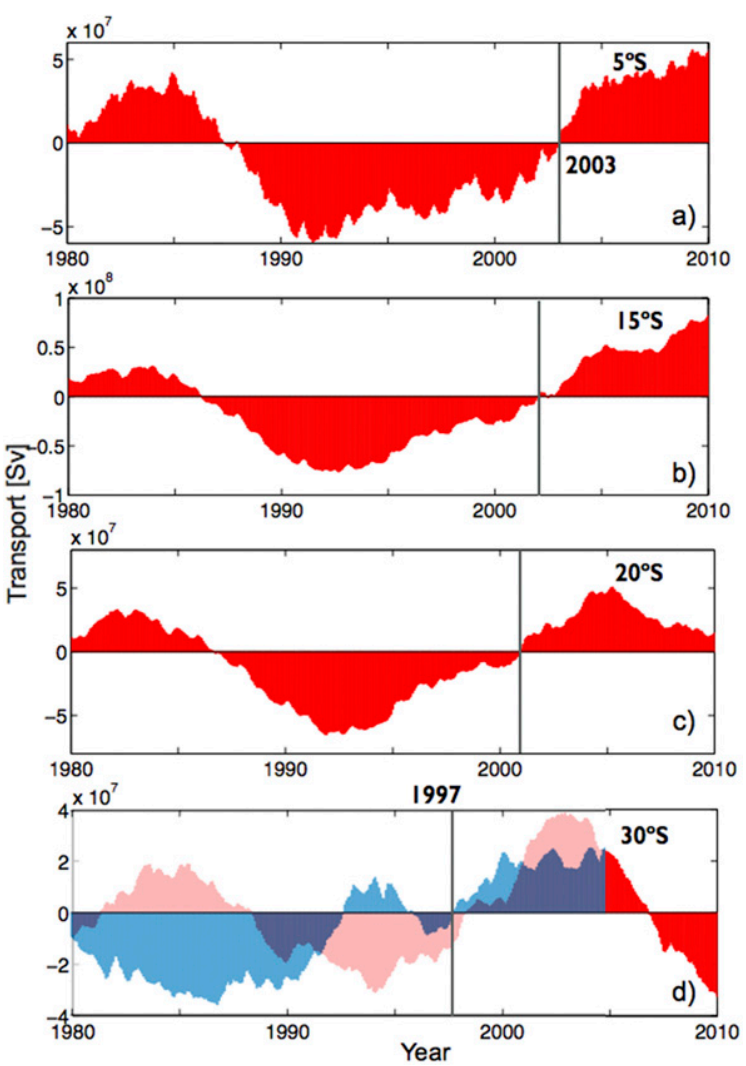

FIG. 12. Regime shift of the Agulhas leakage in the Atlantic meridional volume transport. Shown is the cumulative time of the integrated volume transport from 1980 to 2010 at four selected locations across the southern and tropical Atlantic Ocean at (a) $5^{\circ}$, (b) $15^{\circ}$, (c) $20^{\circ}$, and (d) $30^{\circ} \mathrm{S}$. Each panel shows the residuals of the volume transport, thus representing the lag time in the transport at the depth of isopycnal $\sigma=25.5 \mathrm{~kg} \mathrm{~m}^{-3}$. The blue residual in (d) shows the Agulhas leakage, corresponding to the intrusion of the Indian Ocean waters into the Atlantic.

coefficients presented in Table S1. We examined the cumulative time of the integrated volume transport along each of the latitudinal transects mentioned above and the latent heat flux and precipitation at the western boundary. For this analysis, all original variables' time series since 1980 were used without filtering to match the length of the latent heat and precipitation time series. The respective time lags and correlation coefficients between the integrated volume transport, latent heat flux, and precipitation at $5^{\circ} \mathrm{S}$ can be seen in Fig. S2 and Table S2. Additionally, density probability calculated from the original time series is presented in Fig. S3.

Two regime shifts have been identified by this method. Regime 1 is represented by negative residuals, which indicate a decrease. Regime 2 is represented by positive residuals, which indicate an increase (see Figs. 12 and 13). Figure S3 shows the statistical differences between the named regime shifts.

\section{a. Regime shift 1}

Regime 1 and its negative residuals indicate that Agulhas leakage has a low inflow in the South Atlantic (Fig. 12d, blue shading). The integrated transports across $30^{\circ}, 20^{\circ}$, and $15^{\circ} \mathrm{S}$ show negative residuals regime since 1987 (Figs. 12d, 12c, and 12b, respectively), and the integrated transport in the tropical region, at $5^{\circ} \mathrm{S}$, shows a negative shift since 1988 (Fig. 12a). There is a negative shift in the latent heat flux (Fig. 13b) beginning in 1992, while the precipitation time series exhibits a negative shift from 1988 (Fig. 13c).

These results suggest that regimes 1 and 2 do not seem to be related to each other. They suggest separate mechanisms in the regime shift for leakage and integrated transport, as well as for latent heat flux and rainfall regime.

Heat content from the surface to the depth of the isopycnal $\sigma=25.5 \mathrm{~kg} \mathrm{~m}^{-3}$ was calculated for regime shift 1 . The $40-y r$ anomaly for this regime is presented in Fig. 14a, which shows negative anomalies ranging from $-0.3 \times 10^{8}$ to $0.3 \times 10^{8} \mathrm{~J} \mathrm{~m}^{-2}$. The EKE average was calculated for the regime 1 period (Fig. 15a) where the maximum activity was found concentrated in the Agulhas retroflection region.

The nature of the mechanisms that regulate the dynamic is complex; nevertheless, the results suggest that when Agulhas presents a low inflow (regime 1), the southern and tropical Atlantic dynamics seem to be dominated by the recirculation of the subtropical gyre. The South Atlantic is then dominated by the recirculation process from the South Equatorial Current, the western boundary Brazil Current, and the Subtropical Front (Stramma and England 1999). Thereby, regime 1 is associated with less Agulhas leakage and the gyre is closer to the Sverdrup balance (Wunsch 2011).

\section{b. Regime shift 2}

Regime 2 shows a positive residual in Agulhas leakage transport starting from 1997 (Fig. 12d, blue residual) at the same time as in the transect at $30^{\circ} \mathrm{S}$ (Fig. 12d, red residual). Regime shift 2 can be observed along the South Atlantic in the transect at $20^{\circ} \mathrm{S}$ (Fig. $12 \mathrm{c}$ ), at $15^{\circ} \mathrm{S}$ (Fig. 12b), and in the tropical region at $5^{\circ} \mathrm{S}$ in 2003 (Fig. 12a). The propagation of the anomalies across the South Atlantic, which are exhibited as positive anomalies_-warming (Fig. 5a), salinization tendencies (Fig. 6a), and an increase in the EKE (Fig. 4b) - reveal that the changes in the volume transport in the Agulhas system affect the water properties of the South Atlantic all the way to the equatorial region.

Along with the intensification of volume transport at $5^{\circ} \mathrm{S}$ (Fig. 13a) combined with increased latent heat flux 

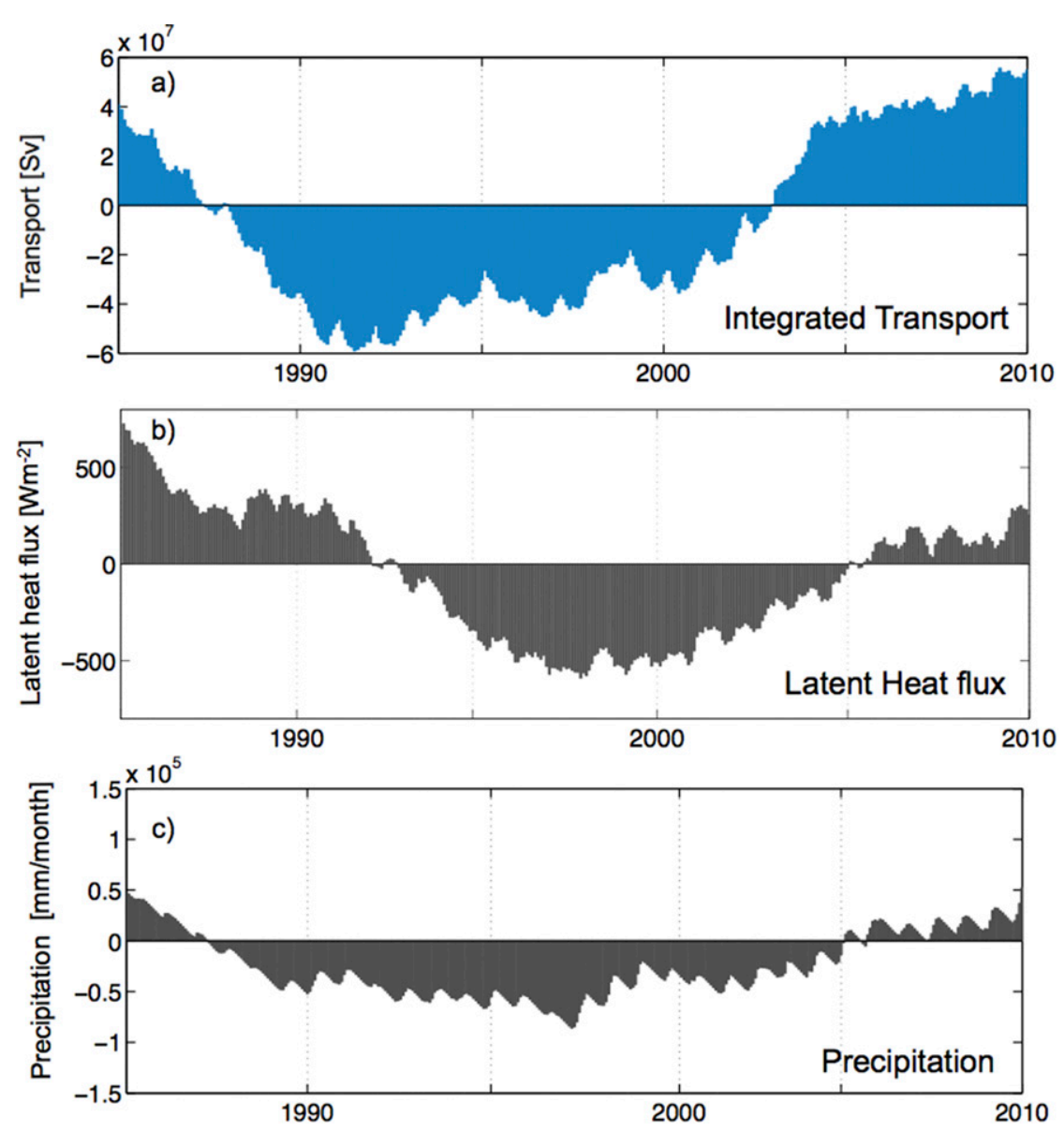

FIG. 13. Regime shift in the (a) volume transport at $5^{\circ} \mathrm{S}$, (b) mean latent heat flux at $1.5^{\circ}$ and $3.5^{\circ} \mathrm{S}$ at $38.5^{\circ} \mathrm{W}$, and (c) mean precipitation over $2.5^{\circ}$ and $4^{\circ} \mathrm{S}$. The time integration of the zonally integrated volume transport was calculated for the period between 1980 and 2010. The cumulative time for the latent heat and precipitation residual were calculated between 1985 and 2014. Therefore, in the figure the period represented spans from 1985 to 2010.

loss (Fig. 13b), an increase in precipitation (Fig. 13c) is observed over the western boundary region of the tropical Atlantic Ocean. The effect of the Agulhas dynamics on the tropical ocean circulation can be observed in the latent heat flux increase and precipitation trends (Fig. 11). Both the heat loss from the ocean in the form of latent heat flux and the precipitation trends near the western boundary of the basin showed a regime shift during 2005 (Fig. 13). Anomalous heat content patterns during the high rainfall regime are displayed in Fig. 14. The heat content shows a positive anomaly in the western region during the second regime with a maximum value of approximately $0.7 \times 10^{8} \mathrm{~J} \mathrm{~m}^{-2}$. Also, the EKE mean for regime 2 (Fig. 15b) shows an increase in the mesoscale activity, mainly in the Agulhas retroflection region and the ring's corridor.

Regime 2 (positive residuals) presents a high inflow of Agulhas leakage transport since 1997 (Fig. 12d). This regime shift can be observed at different latitudes from the Agulhas to the tropical region where the latent heat flux and rainfall have shown signs of changes since 2005. Is this regime shift due to a shift in Agulhas leakage in 1997? Considering that there is also a propagation of anomalies of temperature, salinity, and EKE at the depth of the isopycnal $\sigma=25.5 \mathrm{~kg} \mathrm{~m}^{-3}$, the changes in the western boundary are correlated to the shift of the Agulhas system. These changes are reflected not only in the integrated transport but also in the latent heat flux and precipitation. Figure 14 shows heat content anomalies during the period of regime 2, which exhibit the difference between regimes, this being the most important difference between regimes 1 and 2. The results suggest that when Agulhas leakage increases there is a mechanism where faster propagating anomalies make eddies that dominate the dynamics of the South 

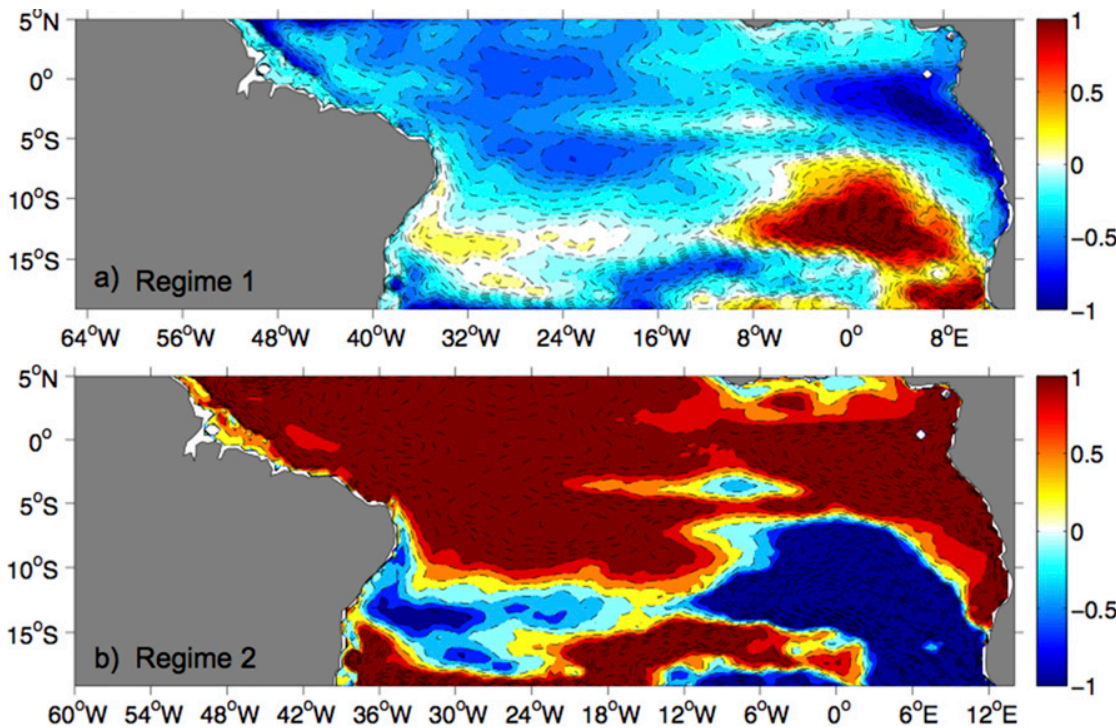

FIG. 14. Heat content $\left(10^{8} \mathrm{~J} \mathrm{~m}^{-2}\right)$ anomaly from surface to the depth of isopycnal $\sigma=25.5 \mathrm{~kg} \mathrm{~m}^{-3}$ from the ATIb0.08 simulation, during (a) low rainfall regimes (1970-2002) and (b) high rainfall regimes (2003-10).

Atlantic. Therefore, during regime 2 the EKE is dissipated by the increase of Agulhas leakage, and thereby in regime 2 the nonlinear effects are augmented because of the increased mesoscale activity associated with more Agulhas rings. Figure 15c shows the differences in the anomalies between regimes, which exhibit positive anomalies in the
Agulhas region and the corridor of rings over the South Atlantic.

\section{Concluding discussion}

According to a numerical experiment with an eddyresolving ocean circulation model, forced with

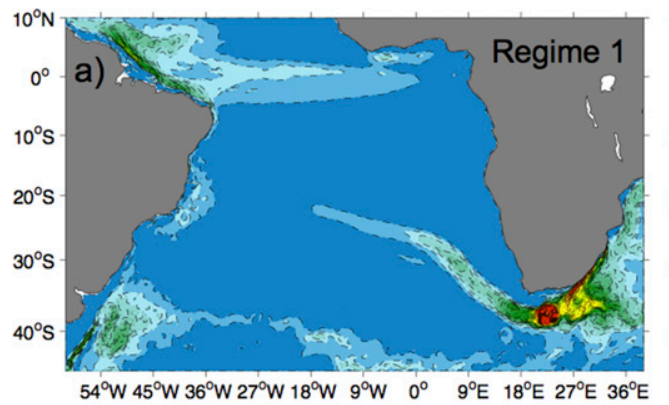

$54^{\circ} \mathrm{W} 45^{\circ} \mathrm{W} 36^{\circ} \mathrm{W} 27^{\circ} \mathrm{W} 18^{\circ} \mathrm{W} \quad 9^{\circ} \mathrm{W} \quad 0^{\circ} \quad 9^{\circ} \mathrm{E} \quad 18^{\circ} \mathrm{E} 27^{\circ} \mathrm{E} 36^{\circ} \mathrm{E}$
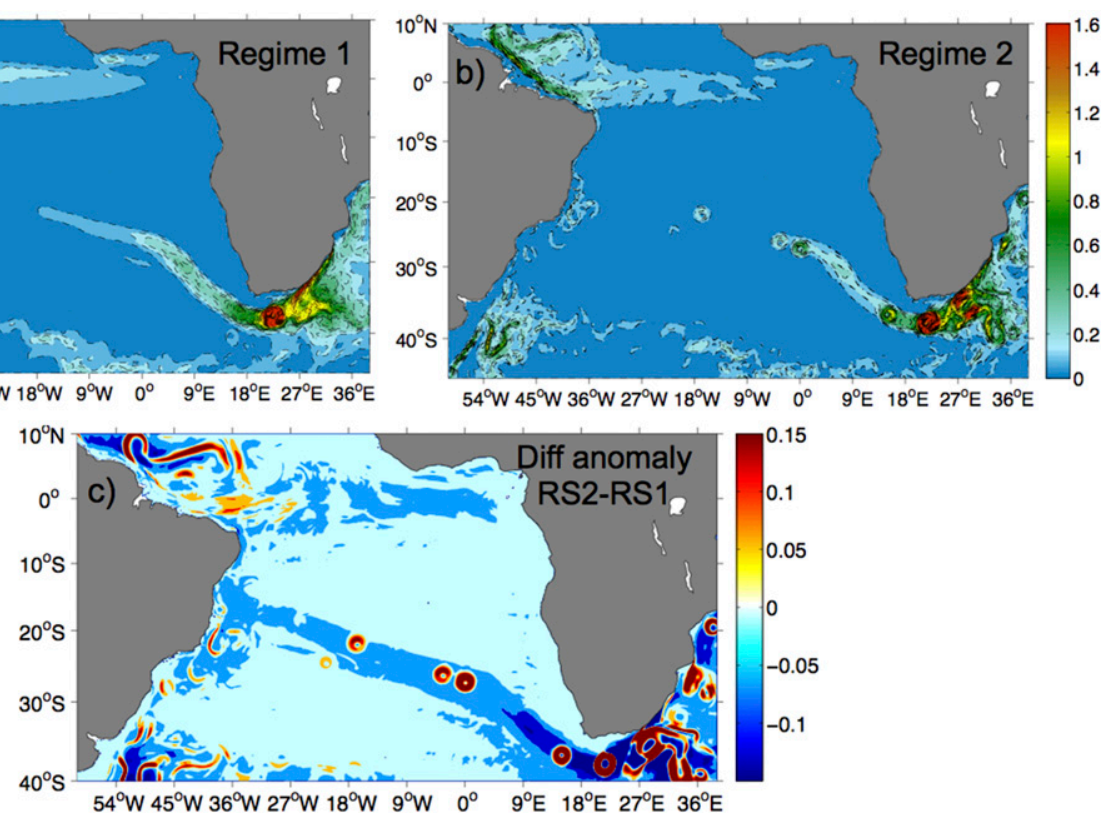

FIG. 15. Average EKE $\left(\mathrm{m}^{2} \mathrm{~s}^{-2}\right)$ from the ATIb0.08 simulation from surface to the depth of isopycnal $\sigma=25.5 \mathrm{~kg} \mathrm{~m}^{-3}$, during (a) low rainfall regimes (1970-2002) and (b) high rainfall regimes (2003-10). (c) The differences in the anomalies between regime 2 and regime 1. 
NCEP-NCAR reanalyses, Agulhas leakage has intensified in the last two decades. The numerical simulation also shows that the changes in Agulhas leakage affect the Atlantic Ocean all the way to the western boundary in the tropical and equatorial regions. The model's estimates of meridional volume transport show an increasing trend in the Agulhas system in the 1970-2010 period. This increase is reflected in the time series of volume transport across different latitudes in the southern and tropical Atlantic.

Two regime shifts in the South Atlantic were identified. One, represented by negative residuals indicating a decrease of properties (regime 1), started by the end of the 1980s. The other (regime 2) is represented by positive residuals starting by the end of the 1990s. The heat loss from the ocean in the form of latent heat flux and the precipitation exhibited an increasing trend near the western boundary. Both times series revealed a positive regime shift starting in 1997 in Agulhas leakage (Fig. 12) and positive regime shift from 2003 onward in the tropical region (Fig. 13).

Heat content anomalies for the two regime shifts in the western region of the tropical Atlantic show a positive anomaly during regime 2 , indicating an increase in heat content, while the negative anomaly remains in regime 1 . Also, the mesoscale activity increased in the Agulhas region and reached the ring's corridor over the South Atlantic. These results suggest the possibility of a positive regime in Agulhas leakage, affecting the regime shifts over the southern and tropical Atlantic. It was shown that rainfall on the northeastern coast of Brazil is tied to the variability of Agulhas leakage.

Assuming that the general fate of Agulhas leakage is mainly unaffected by these changes and follows the pathways and time scales presented here, our results suggest that the positive trend in leakage could invoke a corresponding increase of leakage waters in the western boundary current regime of the tropical Atlantic. Changes in the thermohaline properties along the leakage pathway are of particular relevance (Rühs et al. 2013). The results here support the hypothesis that the modified water mass characteristics in the South Atlantic, due to variations in the Agulhas leakage, are preserved when crossing the Atlantic basin meridionally (Figs. 5 and 6) (Garzoli and Matano 2011; Haarsma et al. 2011; Rühs et al. 2013). This is key to understanding how variations in Agulhas leakage impact the tropical Atlantic deep water, which in turn drives the variations in the South Atlantic MOC (Van Sebille et al. 2010).
This is the first time that an increasing trend in Agulhas leakage has been suggested to be linked to the latent heat flux and rainfall in the western system of the tropical Atlantic. The anomalous propagation pattern associated with the increasing trend of the Agulhas leakage, discussed throughout this paper, has great implications in the South Atlantic. The results of this study, therefore, strongly suggest the need for a detailed analysis of a coupled ocean-atmosphere model in which the dynamics in the vertical structure of the southern and tropical Atlantic together with the Brazil rainfall information are properly simulated. Results presented here highlight the need for continuous improvements in the knowledge of the complex interaction between the South Atlantic and climate variability. Finally, this study demonstrates the need to understand the impact of this regime in the hydrological cycle along the Brazilian coast and the projections of climate change over the tropical Atlantic Ocean.

Acknowledgments. This research is part of the SAMOC-BR and SANSAO Project, funded by the São Paulo State Foundation (FAPESP, Grant 2011/50552-4 and Grant 2008/58101-9). The first author was supported by a FAPESP Post-Doctoral Fellowship (Grant 2013/ 08572-3). E. Campos acknowledges the Brazilian National Council for Scientific and Technological Development (CNPq) for a Research Fellowship (Grant 301117/ 2010-1) and FAPESP (Grant 2015/11366-1). The Heat Flux products were produced by OAFlux from the Woods Hole Oceanographic Institution. The precipitation data were obtained from the Fundação Cearense de Meteorologia e Recursos Hídricos (FUNCEME). We thank Paulo Polito for his support in the discussion of the statistical analysis of the latent heat flux trends and the three anonymous reviewers for their clear-sighted comments.

\section{REFERENCES}

Beal, L. M., and Coauthors, 2011: The role of the Agulhas system in ocean circulation and climate. Nature, 472, 429-436, doi:10.1038/nature09983.

Biastoch, A., and C. W. Böning, 2013: Anthropogenic impact on Agulhas leakage. Geophys. Res. Lett., 40, 1138-1143, doi:10.1002/grl.50243.

,-- , and J. R. E. Lutjeharms, 2008: Agulhas leakage dynamics affects decadal variability in Atlantic over-turning circulation. Nature, 456, 489-492, doi:10.1038/nature07426.

$\longrightarrow,-$, F. U. Schwarzkopf, and J. R. E. Lutjeharms, 2009: Increase in Agulhas leakage due to poleward shift of Southern Hemisphere westerlies. Nature, 462, 495-499, doi:10.1038/nature08519.

Bleck, R., 2002: An oceanic general circulation model framed in hybrid isopycnic-Cartesian coordinates. Ocean Modell., 4, 5588, doi:10.1016/S1463-5003(01)00012-9. 
Bryden, H., H. R. Longworth, and S. A. Cunningham, 2005: Slowing of the Atlantic meridional overturning circulation at $25^{\circ}$ N. Nature, 438, 655-657, doi:10.1038/nature04385.

Castellanos, P., E. J. D. Campos, I. Giddy, and W. Santis, 2016: Inter-comparison studies between high-resolution HYCOM simulation and observational data: The South Atlantic and the Agulhas leakage system. J. Mar. Syst., 159, 76-88, doi:10.1016/ j.jmarsys.2016.02.010.

de Ruijter, W. P. M., A. Biastoch, S. S. Drijfhout, J. R. E. Lutjeharms, R. P. Matano, T. Pichevin, P. J. van Leeuwen, and W. Weijer, 1999: Indian-Atlantic interocean exchange: Dynamics, estimation and impact. J. Geophys. Res., 104, 20885 20 910, doi:10.1029/1998JC900099.

Dong, S., S. Garzoli, and M. Baringer, 2011: The role of interocean exchanges on decadal variations of the meridional heat transport in the South Atlantic. J. Phys. Oceanogr., 41, 14981511, doi:10.1175/2011JPO4549.1.

Fairall, C., E. F. Bradley, J. Hare, A. Grachev, and J. Edson, 2003: Bulk parameterization of air-sea fluxes: Updates and verification for the COARE algorithm. J. Climate, 16, 571-591, doi:10.1175/1520-0442(2003)016<0571:BPOASF>2.0.CO;2.

Garzoli, S. L., and R. Matano, 2011: The South Atlantic and the Atlantic meridional overturning circulation. Deep-Sea Res. II, 58, 1837-1847, doi:10.1016/j.dsr2.2010.10.063.

Haarsma, R., E. Campos, W. Hazeleger, and C. Severijns, 2008: Influence of the meridional overturning circulation on tropical Atlantic climate and variability. J. Climate, 21, 1403-1416, doi:10.1175/2007JCLI1930.1.

- - - S. Drijfhout, W. Hazeleger, and C. Severijns, 2011: Impacts of interruption of the Agulhas leakage on the tropical Atlantic in coupled ocean-atmosphere simulations. Climate Dyn., 36, 989-1003, doi:10.1007/s00382-009-0692-7.

Halliwell, G. R., 2004: Evaluation of vertical coordinate and vertical mixing algorithms in the Hybrid-Coordinate Ocean Model (HYCOM). Ocean Modell., 7, 285-322, doi:10.1016/j.ocemod.2003.10.002.

Hounsou-gbo, G. A., M. Araujo, B. Bourlès, D. Veleda, and J. Servain, 2015: Tropical contributions to strong rainfall variability along the Northeast Brazilian coast. Adv. Meteor., 2015, 902084, doi:10.1155/2015/902084.

Kalnay, E., and Coauthors, 1996: The NCEP/NCAR 40-Year Reanalysis Project. Bull. Amer. Meteor. Soc., 77, 437-471, doi:10.1175/1520-0477(1996)077<0437:TNYRP>2.0.CO;2.

Knorr, G., and G. Lohmann, 2003: Southern Ocean origin for the resumption of Atlantic thermohaline circulation during deglaciation. Nature, 424, 532-536, doi:10.1038/nature01855.

Large, W. G., C. M. James, and S. C. Doney, 1994: Oceanic vertical mixing: A review and a model with a nonlocal boundary layer parameterization. Rev. Geophys., 32, 363-403, doi:10.1029/ 94RG01872.

Liu, W. T., K. B. Katsaros, and J. A. Businger, 1979: Bulk parameterization of air-sea exchanges of heat and water vapor including the molecular constraints at the interface. J. Atmos. Sci., 36, 1722-1735, doi:10.1175/1520-0469(1979)036<1722: BPOASE $>2.0 . \mathrm{CO} ; 2$.

Loveday, B. R., J. V. Durgadoo, C. J. Reason, A. Biastoch, and P. Penven, 2014: Decoupling of the Agulhas leakage from the Agulhas Current. J. Phys. Oceanogr., 44, 1776-1797, doi:10.1175/JPO-D-13-093.1

Rodionov, S., 2004: A sequential algorithm for testing climate regime shifts. Geophys. Res. Lett., 31, L09204, doi:10.1029/2004GL019448.

Rouault, M., P. Penven, and B. Pohl, 2009: Warming in the Agulhas Current system since the 1980s. Geophys. Res. Lett., 36, L12602, doi:10.1029/2009GL037987.

Rühs, S., J. V. Durgadoo, E. Behrens, and A. Biastoch, 2013: Advective timescales and pathways of Agulhas leakage. Geophys. Res. Lett., 40, 3997-4000, doi:10.1002/grl.50782.

Speich, S., and F. Dehairs, 2008: Cruise Report MD 166 BONUSGOODHOPE. Laboratoire de Physique des Oceans, 243 pp.

- , B. Blanke, and G. Madec, 2001: Warm and cold water routes of an O.G.C.M. thermohaline conveyor belt. Geophys. Res. Lett., 28, 311-314, doi:10.1029/2000GL011748.

Stramma, L., and M. England, 1999: On the water masses and mean circulation of the South Atlantic Ocean. J. Geophys. Res., 104, 20 863-20 883, doi:10.1029/1999JC900139.

Van Sebille, E., P. J. van Leeuwen, A. Biastoch, and W. P. M. de Ruijter, 2010: Flux comparison of Eulerian and Lagrangian estimates of Agulhas leakage: A case study using a numerical model. Deep Sea Res., 57, 319-327, doi:10.1016/j.dsr.2009.12.006.

Weijer, W., W. P. M. De Ruijter, A. Sterl, and S. Drijfhout, 2002: Response of the Atlantic overturning circulation to South Atlantic sources of buoyancy. Global Planet. Change, 34, 293 311, doi:10.1016/S0921-8181(02)00121-2.

Wunsch, C., 2011: The decadal mean ocean circulation and Sverdrup balance. J. Mar. Res., 69, 417-434, doi:10.1357/ 002224011798765303

Yu, L., X. Jin, and R. A. Weller, 2008: Multidecade global flux datasets from the objectively analyzed air-sea fluxes (OAFlux) project: Latent and sensible heat fluxes, ocean evaporation, and related surface meteorological variables. OAFlux Tech. Rep. OA-2008-01, Woods Hole Oceanographic Institution, 64 pp.

Zhang, Y., W. B. Rossow, A. A. Lacis, V. Oinas, and M. I. Mishchenko, 2004: Calculation of radiative fluxes from the surface to top of atmosphere based on ISCCP and other global data sets: Refinements of the radiative transfer model and the input data. J. Geophys. Res., 109, D19105, doi:10.1029/2003JD004457. 